Acta Poetica 27 (2)

OTOÑO

2006

\title{
Memoria y voces: Paul Celan
}

\author{
Miriam Jerade Dana
}

Intentaremos abordar el problema de la memoria como memoria de las voces en la poesía de Paul Celan, haciendo hincapié en algunos puntos clave de su poesía, como la fecha, el interlocutor providencial, la intertextualidad.

The following paper will attempt to examine the topic of the memory of voices in the poetry of Paul Celan. From here, we shall focus more particularly on certain key points of Celan's poetry such as dates, providential dialog and intertextuality. 

Miriam Jerade Dana

Universidad de París X, Nanterre

\section{Memoria y voces: Paul Celan}

En el presente ensayo investigaremos la relación entre lectura, memoria, rememoración y poesía en la obra de Paul Celan. Intersección de las voces que la memoria guarda y que la poesía encarna en un decir infinito; pues las voces nunca se reducen a una única y coincidente, ellas pasan, pasan de una a otra orilla como en la traducción, se dirigen también a ese otro que nos interpela y a quien se destina el poema: interlocutor providencial, ${ }^{1}$ quien desde la otra orilla podría recibir, incluso lanzar de nuevo - de manera absolutamente gratuita, sin contratos ni previsiones, incluso sin la exigencia del deber-. "El poema puede ser una botella de mensaje lanzada con la confianza — ciertamente no siempre muy esperanzadora - de que pueda ser arrojada a la tierra en algún lugar y en algún momento, tal vez a la tierra del corazón", 2 escribe Celan; el infinito del poema podría perderse en la inmensidad del mar, ningún

${ }^{1}$ En el discurso con motivo del premio Georg Büchner, "El Meridiano”, Celan escribe: "El poema quiere ir hacia algo Otro, necesita ese Otro, necesita un interlocutor. Se lo busca, se lo asigna" (Celan 2002b, 506). Sobre la influencia de Ossip Mandelstamm en cuanto a la idea del interlocutor providencial, véase el estudio de Marc Crépon 2004.

${ }^{2}$ Paul Celan, "Discurso con motivo de la concesión del premio de literatura de la ciudad libre hanseática de Bremen”, en 2002b, 498. 
poema está a salvo de dicho riesgo; o, por el contrario, la botella llega a la orilla, se enclava en la arena y es recogida por alguien que, providencialmente, estaba ahí; en esta posibilidad está cifrada su esperanza. De la memoria, de la voz, del envío y del mensaje, de la deriva; de todo ello habla el poema, de manera oblicua.

La poesía de Paul Celan conduce a una lectura o relectura de las voces, no sólo de la intertextualidad, sino del momento preciso, del día, del segundo en el que esa voz fue escuchada, y que por ello, forma parte de una experiencia. Experiencia única, "esa" voz y no otra y, a la vez, experiencia múltiple en la rememoración, potencialmente infinita, un instante que puede resurgir en todo momento, hacer converger todas las líneas del tiempo en un único punto y a su vez, proliferar. Traer al presente lo que fue una vez y que, por una evidencia cronológica, no puede volver a ser presente pero que siempre puede representarse.

En la primera estrofa del poema Voces, que abre el libro $L a$ reja de lenguaje, leemos:

VOCES en lo verde

de la superficie de agua rayadas.

cuando el alción, pájaro de nieve, se sumerge,

zumba el segundo:

Lo que estaba de tu parte

en cada una de las orillas,

pasa

segado a otra imagen ${ }^{3}$

${ }^{3}$ [STIMMEN, ins Grün / der Wasserfläche geritzt. / Wenn der Eisvogel taucht, / sirrt die Sekunde: // Was zu dir stand/ an jedem der Ufer, / es tritt / gemäht in ein anderes Bild.] (2002b, 117). 
Voces de una a otra orilla, ${ }^{4}$ pasan imágenes incompletas y, hay algo que no pasa, o que pasa "segado"; así como en la memoria todo recuerdo es incompleto, el recuerdo, para que aflore, debe ser segado; "lo segado" es la posibilidad de la memoria y de la vida. Según otra metáfora de Celan, la imagen pasa a través de un velo suspendido; ${ }^{5}$ en la imagen algo pasa velado. No obstante, el recuerdo es, por antonomasia, revelador: irrumpe. Es difícil recordar un rostro, incluso el más próximo; en cambio, las voces en la memoria siempre son definidas, conservan su tonalidad. ¿Qué pasa por el velo, la metáfora o la imagen, a través de la reja del lenguaje? ¿Qué es lo que se escucha, se ve y se vela en la poesía de Celan? ¿Qué voces recuerda o revela? En el poema antes citado encontramos ruidos de la naturaleza y voces que interrumpen; ella deja de ser natural en el segundo que zumba, que marca el tiempo del hombre. En la segunda estrofa, la voz se dirige a un tú y las voces no son las de la naturaleza, río que corre o alción que se sumerge. ¿Habrá entre estos dos murmullos una dicotomía? Recordemos la frase del Diálogo en la montaña (Gespräch im Gebirg); ahí Celan escribe:

El silencio se hizo, pues, el silencio allí arriba en la montaña. No duró mucho el silencio, pues cuando el Judío viene y encuentra a otro judío, entonces el silencio se acaba pronto, también en la montaña. Pues el judío y la naturaleza son dos cosas distintas, todavía, incluso hoy, incluso aquí. ${ }^{6}$

${ }^{4}$ Frase que puede interpretarse de la siguiente manera: de una a otra boca en el caso del interlocutor, o de una a otra lengua si tomamos la palabra en hebreo $s f a t$, que es a la vez orilla y lengua.

5 “[...] Apenas entra una imagen queda suspendida en el velo y enseguida acude un hilo que se teje, que se entreteje envolviendo la imagen, un hilo del velo; se teje envolviendo la imagen y engendra un niño con ella, mitad imagen, mitad velo". Paul Celan, "Diálogo en la montaña" (2002b, 484).

${ }^{6}$ Paul Celan 2002b, 483. Nos permitimos copiar el texto original para escuchar la voz del yiddish, que por ser un idioma que se crea a partir de la lengua alemana y se basa en su gramática, sólo en yiddish se puede escuchar su similitud y su diferencia, y es por ende, intraducible al alemán. "Still wars also, still dort 
En el Diálogo en la Montaña, que hace referencia, entre otras cosas, a un encuentro con Adorno que no tuvo lugar, la poesía dialogal se impone sobre la poesía bucólica y la naturaleza es invadida por voces que difieren de una experiencia de lo sublime. Como Stéphane Mosès nos muestra en su artículo: "Quand le langage se fait voix", ${ }^{7}$ Celan permite oír ${ }^{8}$ las voces del judío, como memoria del judeo-alemán, el yiddish y, a la vez, deja escuchar la voz de aquel que quiere callar la voz del judío "de nombre impronunciable", y que encontramos en las primeras líneas haciendo referencia a la apelación, común en el nazismo: "der Jud" o en la frase "der Jud und sohn eines Juden" (el judío hijo de judío). Celan hace coincidir estas dos voces, sin borrarlas ni sobreponerlas; vuelve a la canción de infancia, herida por el odio. Y, simultáneamente, Celan escribe con el deseo de dirigirse a un tú, lengua del yo que está solo en un encuentro que no ocurre y se desdobla en la conciencia cual eco. Contrapunto, cuatro voces: dos lúdicas y disonantes, una que parecen dos, canto a capela en búsqueda de otro, del otro.

El "una vez", el presente de las voces vuelve al poema, no sólo como representación, sino como quien, por haber estado presente y habiendo sobrevivido, está en condición de prestar testimonio. ${ }^{10}$ Y no obstante, el testigo ha visto, testigo-ocular, ha escuchado y puede repetirlo. Hay representación en el

oben im Gebirg. Nicht lang wars still, denn wenn der Jud daherkommt und begegnet einem zweiten, dann ist es bald vorbei mit dem Schweigen, auch im Gebirg. Denn der Jud und die Natur, das ist zweierlei, immer noch, auch heute, auch hier". (Celan 2002a, 8).

${ }^{7}$ Mosès 1996.

${ }^{8}$ El judío del Diálogo en la Montaña se hace oír y se deja escuchar ("ließ sich hören") (Celan 2002a, 7).

${ }^{9}$ Ibidem.

${ }^{10}$ Nos estamos refiriendo aquí a la etimología latina de testigo: "testis", quien asiste como tercero, quien está presente y quien subsiste: el sobreviviente. En cambio, la raíz de la palabra en alemán Zeug, Zeugnis, no conlleva de ningún modo la idea del tercero sino que refiere a la procreación, a la generación. Sobre la poesía de Celan y el testimonio, véase Derrida 2004. 
testimonio, una imagen se trae al presente. Celan pregunta en El Meridiano:

¿Y qué serían entonces las imágenes?

Lo que se ha percibido y lo que se ha de percibir sólo una vez, siempre una vez y sólo ahora y sólo aquí. El poema sería así el lugar donde todos los tropos y metáforas nos invitan a reducirles al absurdo. ${ }^{11}$

El poema sería el lugar — ¿utópico? — donde representación y testimonio se unen en la unicidad de la firma y de la fecha. La voz desgarra la imagen de ella misma, es iconoclasta, o la imagen rompe su plasticidad en una presentación única. Excedencia del tiempo en la singularidad del presente. Nadie puede testimoniar por el testigo, tomar su lugar, remplazarlo. Cito el último párrafo del poema Aschenglorie, Aureola de cenizas:

Niemand

zeugt für den

Zeugen $^{12}$
Nadie

testimonia por el

testigo

El poeta no habla en lugar del otro, nadie testimonia por el testigo, él es irremplazable, aún si ya no puede hablar; el poeta presta su voz para que algo o alguien hablen a través de él. Tal es la dimensión profética de la poesía.

El poeta es el único que puede prestar testimonio de esa imagen, de ese momento, de esa fecha y, a la vez, crear un lenguaje inédito, firmar. El poema, como diría Derrida citando a Krieger, "constituye su propia poética", ${ }^{13}$ es evento en el cuerpo verbal de su singularidad, a la vez única e iterable. Todo poema promete una experiencia otra de la lengua, y a la vez, todo poema es por su iteración, la posibilidad de memorizarlo, de recitarlo.

${ }^{11}$ Celan 2002b, 507.

12 Ibidem, 235.

${ }^{13}$ Ibidem, 521. 
Tal vez el único testigo del Diálogo en la Montaña sea la lengua alemana: del exilio del yiddish, que sólo ella puede escuchar como experiencia del idioma, de lo intraducible, ${ }^{14}$ la lengua alemana testigo de su autodestrucción en la lengua del Tercer Reich, como apropiación ideológica de las palabras y el empobrecimiento del vocabulario; ${ }^{15}$ del exilio ya de por sí del yiddish de su propia matriz, de su silencio. Testigo también de la poesía de Celan, del evento que abre a la lengua a una nueva posibilidad sobre sí misma, a través de una voz.

Al Diálogo en la Montaña, Celan hace referencia, como evento y como escrito, en "El Meridiano":

Y hace un año, en recuerdo de un encuentro malogrado en Engadina, redacté una pequeña historia en la que hice atravesar las montañas a un hombre "como Lenz". Tanto una vez como otra había escrito mi procedencia a partir de un " 20 de enero", de mi "20 de enero". Me he encontrado... conmigo mismo. ${ }^{16}$

En este párrafo se cruzan la lectura del Lenz de Büchner y el escrito del Diálogo en la montaña. El meridiano podría ser la línea que une ambas en una fecha, el 20 de enero de Lenz se convierte en "mi 20 de enero" y la lectura es experiencia de lectura, también un momento preciso, que la memoria trae al presente, el " 20 de enero", más de un "20 de enero"; el de Lenz y el de Celan leyendo a Lenz.

Paul Celan fue un lector ávido; su biblioteca personal contaba con más de 3000 ejemplares, sin contar las múltiples lecturas

${ }^{14}$ El yiddish que, según Kafka, es un "ladrón de gramática", deforma o juega con el alemán introduciendo el hebreo; de ahí la imposibilidad de hacer una traducción al alemán. Sobre la relación entre el yiddish y el alemán y la constitución del primero en tanto que "idioma", según el concepto de Derrida, véase Crépon 2005.

${ }^{15}$ A este respecto véase la obra de Victor Klemperer, La lengua del III Reich, Barcelona, Minúscula, 2001. O la obra de Jean-Pierre Faye, Langages Totalitaires, Paris, Hermann, 1972.

16 "El Meridiano", en Celan 2002b, 509. 
que Celan realizaba en la biblioteca de l'École Normale, su lugar de trabajo. Entre sus libros se podían contar obras de la literatura mundial en varios idiomas; una gran parte estaba consagrada a la filosofía; había igualmente estudios sobre judaísmo, así como libros sobre temas diversos, entre ellos varios tratados de herbolaria. La obra de Celan, por sus múltiples referencias y la dificultad de su interpretación, ha llevado a los investigadores a hacer una radiografía de las lecturas, a buscar las marcas del poeta en el texto, pues Celan marcaba el texto que leía, fechaba sus lecturas, escribía en los bordes, tachaba parte de una frase o de un párrafo, marcaba con un círculo algunas palabras o proposiciones y a veces marcaba con la letra $i$, de idea, la génesis de un poema; como da cuenta el trabajo de Alexandra Richter, Patrick Alac y Bertrand Badiou, La bibliothèque philosophique de Paul Celan. ${ }^{17}$

Además de haber sido un lector atento, Celan tradujo a una cantidad considerable de autores, en siete idiomas distintos. Tradujo del francés a Guillaume Appolinaire, Aimé Césaire, René Char, Paul Eluard, Jules Supervielle, Arthur Rimbaud, Henri Michaux, Paul Valéry y Paul Verlaine. Del hebreo, cotejando con las traducciones de Franz Rosenzweig, a Yehuda Halevi; del ruso, a Sergej Jessenin, Ossip Mandelstamm, Boris Pasternak; algunos escritores rumanos como Discipol Mihnea, a quien Celan traduce en su juventud al yiddish, y autores del yiddish, como Itzig Manger y Halper Lejvick, que traduce al alemán. Traduce del portugués a Fernando Pessoa; del inglés a Emily Dickinson y a Shakespeare; del italiano a Giuseppe Ungaretti. ${ }^{18}$

${ }^{17}$ Alac, Badiou, Richter 2004.

${ }^{18}$ Sobre Celan y la traducción, me permito remitir a la obra Celan als Übersetzer, "Fremde Nähe", 1997. Esta obra corresponde a la publicación de una parte del catálogo sobre Celan de los archivos de Marbach am Neckar, donde se encuentra la mayoría de los documentos originales, así como una parte de la biblioteca de Paul Celan. 
Habría que pensar en la calidad de lectura que pide la traducción, el retorno a una palabra, a una frase antes de encontrar su homónima en otra lengua; traducir un poema es rescribirlo, es invitarlo a otra posibilidad de ritmo y de sonoridad, es también memorizarlo para dejar que acontezca el traslado. Celan traduce al alemán y en ese alemán poético escribe, vuelven en sus poemas frases de otros poemas, de las lecturas, de la traducción. Mi cuestionamiento estaría del lado de este retorno o invitación de los textos al poema, cuál es el lugar aquí de la cita, de la evocación o de la rememoración unido a la firma, y sobre todo a la fecha que, según Derrida, es otro modo de firmar, ${ }^{19}$ de referirse a la experiencia, a lo que alguna vez tuvo lugar y que por ese una vez, puede ser traído a la memoria. Celan es también un interlocutor providencial de otros escritores, que por gracia o por azar recogió el mensaje de la botella y lo hizo atravesar hasta la otra orilla; y, no obstante, lo providencial del lector y del poema está inscrito en el tiempo, y no en la eternidad o en lo atemporal; el poema en Celan no es una obra universal, válida en todo tiempo y espacio; el poema es sólo por alguien que abre la botella de la palabra escrita a la voz, el poema es la intimidad de la cita, lo fugaz del encuentro; no obstante inscritos en la eternidad por lo irrecuperable del tiempo y lo irremplazable del ser.

Para mostrar la intertextualidad o la invitación de otras voces al poema, daré como ejemplo la segunda estrofa del poema Voces:

Stimmen vom Nesselweg her.

Komm auf den Händen zu uns.

Wer mit der Lampe allein ist, hat nur die Hand, draus zu lesen.

19 "Dans certaines conditions du moins, dater revient à signer" (Derrida 1986, 29). 
Voces desde el camino de ortigas:

Ven con las manos hasta nosotros.

Quien está solo con la lámpara

sólo tiene la mano para leer.

El "Nesselweg" — camino de ortigas - trae a la memoria un poema traducido por Celan "Bei den gelben Nesseln" de Jessenin, una voz rusa, una voz que habla del sufrimiento. En el segundo verso se escucha la novela Reiterarmee [Ejército de caballeros], de Isaak Babel, en la que un joven que hace de bufón "camina con las manos". En dicha novela, hay una joven judía que es violada por soldados rusos, sufrimiento al cual este joven, llamado "Kikin", es absolutamente insensible. En los dos últimos versos encontramos un poema de Supervielle traducido por Celan intitulado "Flammenspitze", "Pointe de flamme", en el que una mano acaricia la flama de una lámpara con el fin de cerciorarse de que ella sigue viva. ${ }^{20}$ Esta misma estrofa del poema Voces viene a la memoria de Celan en "El Meridiano", y antes de reescribirla idéntica en otro texto, subraya su inserción en el tiempo vital: "Hace unos años escribí un pequeño cuarteto: este". ${ }^{21}$ Después de citar la estrofa seguida de un párrafo del Diálogo en la Montaña, Celan dice que son caminos los que se recorren con los poemas —aún si para Celan el poema se adelanta, nos rebasa-. ${ }^{22}$ En "El Meridiano" escribe:

Pero a la vez son también, sin duda, entre tantos otros caminos, caminos en los que el lenguaje encuentra su voz, son encuentros, caminos de una voz hacia un tú que atiende, caminos de la criatura, proyectos de una existencia tal vez, una

${ }^{20}$ Quisiera agradecer a Alexandra Richter el haberme procurado las referencias intertextuales de este poema.

21 "El Meridiano", en Celan 2002b, 508.

22 "Hay otros caminos más cortos, lo sé. Pero sin duda la poesía también se nos adelanta a veces" [La poésie, elle aussi, brûle nos étapes.] (ibidem, 504). 
proyección anticipada hacia sí mismo, a la busca de sí mismo... Una especie de retorno al hogar. ${ }^{23}$

Habría que preguntarse ahora, hasta dónde la rememoración del poema o su llegada intempestiva dentro del discurso, permiten ese camino hacia, esa dirección, ese encuentro con el otro y consigo mismo. Cada poema lleva su 20 de enero, es el acontecimiento de una voz en el corazón mismo de la lengua, la lengua como dialogismo, es, yo diría, la invención de un verbo conjugado en dativo. El poeta cuando por fin se encuentra, está dirigiéndose al otro, al interlocutor providencial. El 20 de enero que rememora, que otorga, es ya también su 20 de enero.

El poema es a la vez el retorno al hogar y el camino donde el lenguaje encuentra su voz a través del poeta, de su experiencia, de su memoria, incluso herida — por la imposibilidad de retorno, de sus padres a casa y de él a casa de sus padres-. El poema "Voces", del cual ya hemos citado las dos primeras estrofas, nos habla también de ese no retorno del tiempo, la voz de la madre y lo que, pese a la intención del tiempo, del año con año, grita lo irreparable:

Voces ante las que tu corazón

al corazón de tu madre se repliega.

Voces desde el árbol de horca

donde el leño de otoño y el de primavera los anillos cambian y cambian. ${ }^{24}$

Esto nos lleva a pensar el poema, a la vez como un encuentro de citaciones, de voces ajenas, y como una autobiografía que se entrega, se dona, se da, al otro, a ese otro para quien se escribe el poema. Pero no sólo para quien se escribe el poema,

${ }^{23}$ Ibidem, 509

24 "Stimmen, von denen dein Herz / ins Herz deiner Mutter zurückweicht. / Stimmen vom Galgenbaum her, / wo Spätholz und Frühholz die Ringe / tauschen und tauschen" (Celan 2002b, 117). 
sino también para quien se lee. En una carta de Paul Celan a su mujer, Gisèle Celan-Lestrange, fechada el 14 de agosto de 1952, leemos: "Je lis beaucoup pour pouvoir un jour écrire un nouveau livre pour vous" ${ }^{25}$ [Leo mucho para poder un día escribir un nuevo libro para usted].

En Celan la cita no sólo envía, se da cita con un autor en una fecha precisa, y firma. A veces las citas vienen por doble envío, como en "El Meridiano", donde Malebranche llega a través de Benjamin refiriéndose a Kafka, y Pascal pasa por Chestov. Celan piensa la cita como algo que se puede compartir y, de hecho, llegó a pensar en hacer una colección de citas, al igual que Benjamin, que fuera un libro para los amigos. ${ }^{26}$ Así testimonia una página de su diario:

Domingo 9 de mayo (1965), en la tarde, cuatro menos cuarto. [...]

Leí un poco de Kafka, los cuentos.

[...]

En Kafka, "El primer viaje largo en tren" —un texto que apenas he leído más de un vez- la frase (p. 299): "Yo, en cambio, me siento psíquicamente al desnudo cuando alguien se sienta a mi lado".

$[\ldots]$

Completar la cita de Kafka: "Yo, en cambio, me siento psíquicamente al desnudo cuando alguien se sienta a mi lado. En

${ }^{25}$ Unas líneas antes en la misma carta: "Une seule chose TRÈS curieuse qui m'est arrivée hier soir, "sur la brune": j'ai trouvé, chez un bouquiniste près de Notre-Dame, un troisième (!) Kafka dans l'édition originale: "Das Urteil”, prix: 100 francs. Notre bibliothèque s'est considérablement enrichie ces derniers jours. Je dois vous signaler, entre autres (oh, excusez-moi encore d'être si dépensier!) une édition —assez rare, je crois— numérotée de "Charmes" de Valéry (200 frs). Ensuite Correspondance de Nietzsche avec son ami Overbeck (en allemand) et plusieurs petites brochures de Heidegger et de Jaspers, toutes très bon marché et dans l'édition originale". Paul Celan et Gisèle Celan-Lestrange 2001, 35.

${ }^{26}$ El libro para los amigos es un gesto muy presente en la literatura alemana, es una especie de colección de citas y reflexiones, el más conocido tal vez es el Buch der Freunde de Hugo von Hofmannstahl. 
resumidas cuentas, no tenemos a priori un ojo prestado para hacer frente a este tipo de individuo, es necesario, primero, dirigir los ojos hacia él".

Confeccionar eventualmente $-\mathrm{y}$ no es la primera vez que se me ocurre - un "Libro de los amigos" a partir de esta clase de citas. ${ }^{27}$

Celan acumula citas, las aprende de memoria, las recuerda - a veces mal, para traerlas al poema desde otro lugar-; hay correspondencias, lazos entre la citación y la cita a la que sólo uno debe asistir, único por la fecha que tuvo lugar un día, que abre la existencia con el nacimiento, y la fecha que la clausura, de la cual no tendremos memoria alguna. El "yo" es memoria y desmemoria. Celan escribe en el Diálogo en la montaña:

He venido con el bastón, yo y ningún otro, yo y no él, yo con mi hora, la inmerecida, yo, al que le ha tocado el destino, yo, al que no le ha tocado, yo con la memoria, yo, el de la mala memoria (Gedächtinsschwache), yo, yo, yo... ${ }^{28}$

Una frase sin embargo nos retiene: mala memoria o, en alemán, memoria débil. Sabemos que Celan tenía una memoria prodigiosa, mas confiesa una memoria débil. El recuerdo llega a través de la herida de la propia vida, de otra fecha. Llega y coagula, con la lengua, la propia, la ajena. Coagula con las lecturas, converge con los nombres. En una carta del 23 de noviembre de 1967, que acompaña al poema "Coagula", ${ }^{29} \mathrm{Ce}$ lan escribe a su amigo Peter Solomon:

${ }^{27}$ Diario inédito. Aparece como epígrafe en Alac, Badiou, Richter 2004. Traducción libre al español.

${ }^{28}$ Celan 2002b, 485.

29 “COAGULA /// También tu / herida, Rosa. // Y la luz de los cuernos de tus / búfalos rumanos / en el lugar de la estrella sobre / el lecho de arena, en la / parladora, de rojas / cenizas poderosa / retorta."

[COAGULA /// Auch deine / Wunde, Rosa. // Und das Hörnerlicht deiner / rumänischen Büffel / an Sternes Statt überm / Sandbett, im / redenden, rot- / aschengewaltigen / Kolben] (Celan 2002b, 242). 
[...] Los bisontes rumanos percibidos por Rosa de Luxemburgo a través de los barrotes de la prisión, convergen con las tres palabras del "Médico rural" de Kafka $-\mathrm{y}$ con el nombre: Rosa. Coagulo, intento hacer coagular. ${ }^{30}$

Las voces también coagulan, las del pasado, las de los muertos, las del traductor, las del poema y las de todos los poetas, la del ausente... Ellas se guardan en la memoria, débil. ¿Habrá alguna voz que reconforte la memoria herida?

La última estrofa del poema "Voces" comienza: Ninguna Voz. Las demás estrofas que inician con la palabra: Voces, se confrontan, casi se golpean ante Ninguna. No es la nada, es el poema que llega, no es la voz de la rememoración, sino Ninguna Voz, lo que se ofrece al pensamiento:

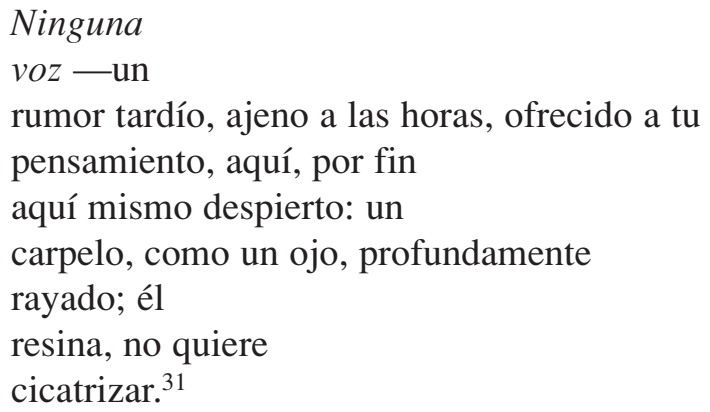

La memoria sólo es posible gracias a una voz materna, a una primera interpelación. La lengua da cuenta de esta dimensión dativa de la palabra y de la memoria, y de la posibilidad de ambas como apelación. El poema las presenta en un decir único. Se expone a la voz que llega a través de la memoria y a aquella que se espera, que ignora porque no puede prever su

${ }^{30}$ Alac, Badiou, Richter 2004, xx.

${ }^{31}$ [Keine / Stimme -ein / Spätgeräusch, stundenfremd, deinen / Gedanken geschenkt, hier, endlich / herbeigewacht: ein / Fruchtblatt, augengroß, tief / geritzt; es / harzt, will nicht / vernarben] (Celan 2002b, 118). 
respuesta, la voz de aquel a quien se dirige el poema. Voces, con ella y con ellas, por ellas y a través de ellas, vamos, desde siempre y hasta siempre.

Y alguna vez, quizás sólo una vez, cada vez una vez única, quizás inmemorial, ajeno a las horas, en un aquí y un ahora del cual sólo el poeta puede dar testimonio; ¿qué?, una resina que no cicatriza, un ojo rayado que no ha perdido su lucidez, algo, más bien "ningún" se ofrece al pensamiento: Ninguna Voz: El poema.

\section{REFERENCIAS}

Alac, Patrick, Bertrand Badiou y Alexandra Richter, 2004. La bibliothèque philosophique de Paul Celan, Paris, Éditions rue d'Ulm.

Celan, Paul, 1998. Choix de poèmes, trad. Jean Pierre Lefebvre, Paris, Gallimard.

—, 2002a. Gespräch im Gebirg, Aachen, Rimbaud Verlag.

—, 2002b. Obras completas, trad. María José Reina Palazón, $3^{\text {a }}$ ed., Madrid, Trotta.

Celan, Paul y Gisèle Celan-Lestrange, 2001. Correspondance, ed. Bertrand Badiou con la colaboración de Eric Celan, Paris, Seuil.

Celan als Übersetzer, "Fremde Nähe”, 1997. Deutsche Schillergesellschaft Marbach am Neckar.

CRÉPOn, Marc, 2004. Terreur et poésie, Paris, Galilée.

Derrida, Jacques, 1986. Schiboleth pour Paul Celan, Paris, Galilée.

—, 2004. "Poétique et politique du témoignage", L'Herne, ed. Marie-Louis Mallet y Ginette Michaut, Paris, Éditions de 1’Herne.

—, 2005. Langues sans demeure, Paris, Galilée.

Mosès, Stéphane, 1996. "Quand le langage se fait voix. (Entretien dans la montagne)", en Contre-jour. Études sur Paul Celan, actas del Colloque de Cerisy, ed. par Martine Broda, Paris, Cerf. 